\title{
DESCRIPTION OF AN IMPROVED STEAM BOILER FOR LOCOMOTIVE AND OTHER ENGINES.
}

The improved construction of steam boiler, forming the subject of the present paper, is shown in Figs, 1 to 7, Plate 85.

Fig. $I$ is a longitudinal section of a locomotive engine, showing the general arrangement of the boiler and firebox, and the frame and wheels.

Fig. 2 is a longitudinal section of the firebox to a larger scale.

Fig. 3 shows half a sectional plan of the firebox, and half a plan with the outer shell of the boiler removed.

Fig. 4 is a transverse section in front of the fire grate, showing the tube plate and tubes.

Fig. 5 is a transverse section through the fire grate.

Fig. 6 is an end elevation.

The external casing $A$ of the firebox is cylindrical in form, and rivetted to the barrel of the boiler. The back end plate $B$ is flanged round the entire circumference, and inserted into the external casing $A$, to which it is rivetted with the flange outwards. The plate $B$ has two openings in it, the upper one $\mathrm{C}$ for firing the furnace, and the lower $\mathrm{D}$ for regulating the admission of air under the furnace bars, allowing access to the ash space for the removal of ashes, and enabling the fireman to work the damper, \&c. ; these openings are supplied with doors working on hinges or sliding in grooves. EE are manholes into the interior of the boiler, with suitable covers. F is a receiver for the collection of scale and deposit, and is supplied with a cover and also a screwed plug to facilitate the removal of the deposit. Plugs $G$ are also provided at the end of the boiler for allowing the deposit to be cleared out of the water space below the grate. $\mathrm{H}$ is an opening to admit air from the exterior of the boiler, and is supplied with a hinged or sliding damper, arranged to be worked from the foot plate.

The firebox $I$ is cylindrical for the greater part of its length, and enlarged at the front end to the form of the tube plate $K$, as shown in Figs. 3 and 4, so as to form a combustion chamber and at the same time admit of the greatest possible number of tubes. The front end of the firebox may also be made bell-mouthed to the form of the tube plate, as shown in Fig. 7, but the writer prefers the arrangement shown in Figs. 3 and 4 . The tube plate $K$ and the end firebox plate $L$ are both flanged and rivetted to the firebox. The firebox is securely held and stayed in 
position by stays and roof girders. $M M$ are inverted bridges or water spaces rivetted to the cylindrical portion of the firebox, which has holes cut in the roof, as shown in Fig. 3, so as to allow of the admission of water to the bridges $M$, and the escape of the steam generated in them. These bridges, besides adding to the strength of the firebox and giving additional heating surface, are intended to mix up the flame and smoke from the fresh fuel near the fire door, and deflect it against the red fire.

The fire bridge $\mathrm{N}$ is made in two portions; the lower part is a hollow metallic bridge, perforated with holes to admit air, and the upper portion is made of perforated fire bricks or tiles. The air admitted by the holes in the lower part will be heated in passing through the fire brick, and on entering the firebox comes in contact with the smoke and flame deflected by the water spaces M, upon which it acts like a series of blow pipes. The air thus mixing with the flame in the combustion chamber between the fire bridge $\mathrm{N}$ and the tube plate $\mathrm{K}$ causes the unconsumed gases to ignite before passing through the tubes. A hinged door $O$ is provided at the bottom of the fire bridge, with a handle to work from the foot plate, for the purpose of letting out any ashes that may be drawn over the bridge. $P$ is a hand lever for giving a slight motion to the fire bars, so that a clear fire may be maintained, and the deterioration of the bars by burning prevented; in locomotives the movement may be given to the fire bars by a motion taken from the axle or axle boxes of the engine, according to convenience.

The whole of the boiler and firebox is of wrought iron, excepting the tube plate $\mathbf{K}$, which is of copper. The size of boiler shown in the drawings is 4 feet outside diameter, being made cylindrical throughout and about the same diameter as the width of the outside shell of an ordinary locomotive firebox. The heating surface is about the same as in the ordinary boilers of the same length.

In designing the boiler above described, the object of the writer has been the combination of the following advantages :- $a$ form and arrangement of boiler economical in construction, possessing great strength and lightness, occupying little space, and so constructed that the parts most liable to deterioration can be removed with less labour and cost than in ordinary boilers; having also additional facilities for clearing out the deposit and for the consumption of smoke. With regard to locomotive boilers, a special object has been to allow of any disposition of the wheels, with a view to the best distribution of the weight; and in the boiler now 
described, the firebox being contained within the cylindrical shell of the boiler, the latter can be carried farther back on the foot plate, and the trailing wheels can be placed below the firebox, as in Fig. 1 .

The Chaimman enquired whether there were any boilers at work on the construction described in the paper.

Mr. Allan said that there were not any at work at present.

Mr. RAMSBotrom asked what was the total area for admission of air into the space below the fire grate.

Mr. Allan replied that the opening below the fire bridge was 16 inches wide by 10 inches long, besides the back end door nearly as large, which gave an ample area of opening for the passage of the air through the grate. A larger grate area than usual was adopted for the purpose of burning coal, and by the arrangement of the furnace much of the smoke would be consumed.

Mr. FaIrbaIRN enquired whether there was not some danger of burning the portion of the boiler below the ashpan, where the deposit was formed, and where there was only a narrow water space.

Mr. ALLan explained that the boiler could be readily blown out at the receptacle provided there, so as to prevent accumulation of deposit at that part; and it was not exposed there to the direct heat of the fire, the ashpan being open to the air. There was less obstruction than usual from the stays around the firebox, as they were 7 or 8 inches apart instead of 4 inches, in consequence of the firebox being cylindrical without flat sides.

Mr. Fothergilu observed that the firebars were placed transversely, and asked whether that arrangement was found as good as the ordinary longitudinal position.

Mr. Allan said the firebars were shorter in length when placed transversely; and the clinkers were prevented from adhering to the bars and a clear fire constantly maintained by the vibrating motion given to the bars.

The Chairman proposed a vote of thanks to Mr. Allan for his paper, which was passed, and expressed a wish that he would give the results of the boiler, when a trial of it had been made.

The following Paper, by Mr. Walter Neilson, of Glasgow, was then read :- 

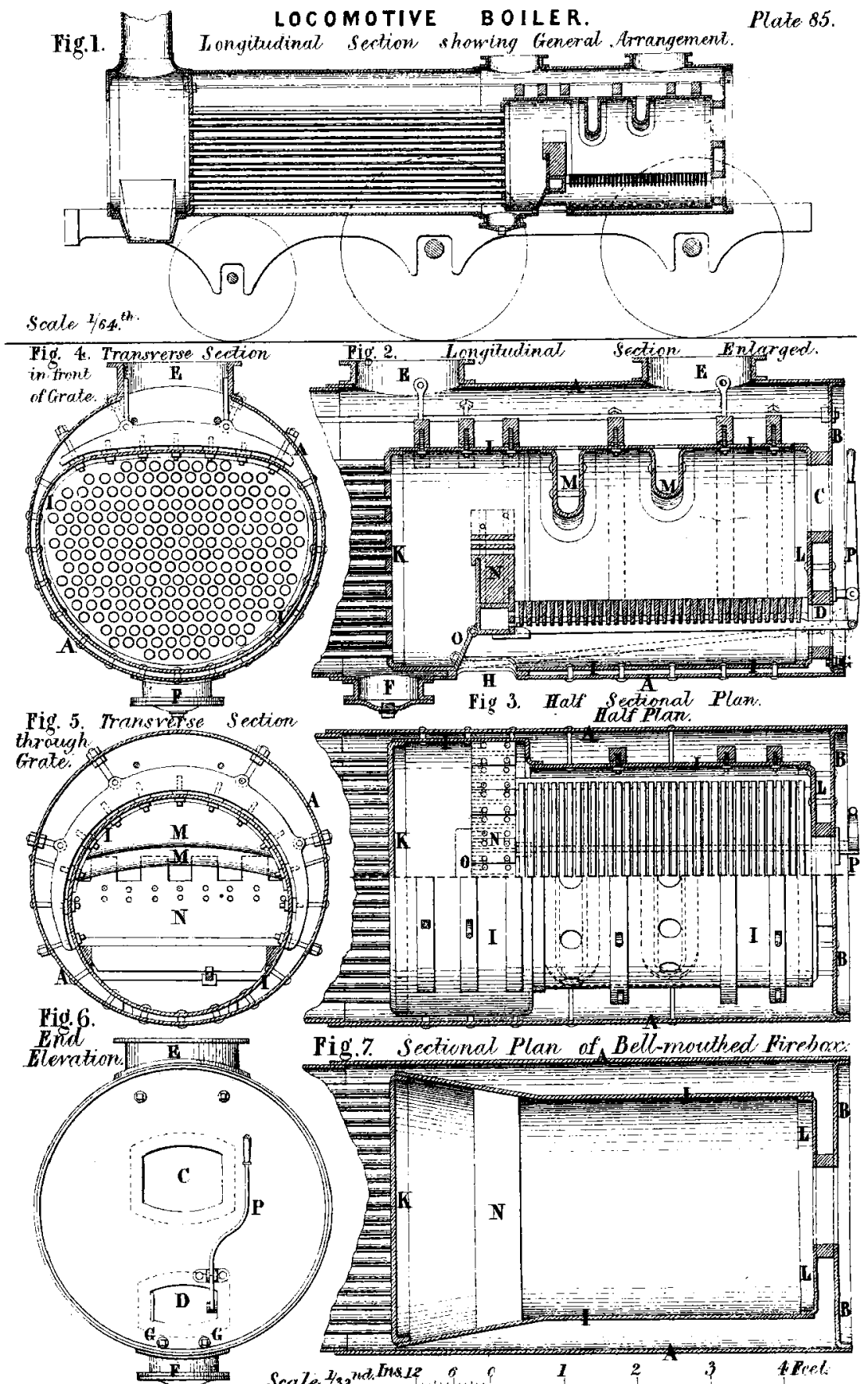

(Procedings Int . ME. 1856. Page 233). 